\title{
The Study of the Syntactic Translation Technique in College English Translation Teaching
}

\author{
Lei Liang \\ School of Foreign Studies, Xi'an University
}

Keywords: College English; Translation teaching; Syntactic translation technique; The study

\begin{abstract}
The translation teaching has always been a difficult point in English teaching, especially in college English translation teaching. It contains complex contents, which is a very important reason why many students cannot master the translation skills and lots of teachers complain about the difficulty of teaching translation class. In fact, as far as the translation teaching be concerned, many other techniques will be able to help us reduce the difficulty in the translation process itself, except for the basic English knowledge. However, what we should do first is to be familiar with the sentence structure and realize the inherent features containing in a sentence, and then to translate it from the perspective of the syntactic features. Achieving this goal will be very meaningful for improving the current college English translation teaching.
\end{abstract}

\section{Introduction}

As a matter of fact, the ability of E-C translation can measure a student's comprehensive English level, therefore, the translation teaching has always been a difficult point in English teaching. According to the classification of some related literature documents, we can divide the translation into four processes: analyzing the source text; changing the source text into the target language; recombining the meaning of the source text on the basis of the features of target language; modifying the translation, and that is a basic translation process. From the above analysis, we can see that analyzing the source text is the beginning of the whole translation, and it is also the process in which students will make the most mistakes, which is very common in college English translation teaching. Therefore, what we should do next is to improve this situation from aspect.

\section{The Functional Identification of the English Syntactic Components}

From the perspective of the traditional grammar, a sentence is a product which is arranged by a series of words on the basis of some linear rules. Therefore, if we want to analyze the syntax, we should first do some researches about the features of the words. To be specific, this process can be divided into two small ones: classifying according to the word class; identifying the function of words according to the Subject and the Predicate. Generally speaking, an English syntactic component will contain more than two modifying attributes, and from this aspect it is very necessary to clarify the syntactic elements. Therefore, before students begin their translation practice or during the process of translation teaching, what we should do is to analyze the syntax of the source sentences, which is also the beginning of the study and teaching of the syntactic translation technique. For example, in a sentence like this: "A girl in white walked into the hall.", the prepositional phrase "in white" serves as the postpositive attribute and modifies the Subject "a girl”.

Another example is the following sentence: "Smaller class sizes in early grades translated into student scoring higher on math tests in later grades in Tennessee's Experiment to see if smaller class improved education, a study said on Friday". The main structure of this sentence is "a study said on Friday". If we want to find the main structure, we should begin with the object clause which follows "said". However, the syntactic function of the infinitive phrase "to see if smaller classes improved education" in this sentence cannot be determined. What we can ensure is that this infinitive phrase is the postpositive attribute of "experiment". When we meet with such difficulty, we should come back to the basic translation process and integrate the meaning of the source sentence according to 
the existing information, which can help us to get the correct translation. From the above analysis, it can be concluded that whether we can identify the syntactic function correctly influences the effect of translation in a direct way. Therefore, in the process of college English translation teaching, it is necessary for us to enhance students' ability of identifying the syntactic function. In order to achieve this goal, the first thing we should do is to let students have a correct understanding of the difference between Chinese and English sentence structure. In addition, students should also have accumulation in their daily practices except for the class teaching.

\section{The Basic Overview of E-C Translation Technique}

The aim of college English teaching is to improve students' comprehensive English ability, in which the translation ability is a very important point. However, the college English major at present is paying more attention to the ability of listening, speaking, reading and writing, and the emphasis on translation is relatively scarce, not to mention the lacking of the practical translation teaching technique in other majors, which can be realized from the CET-4 from 1995 to 2004: there is no such relative questions about the translation ability. With the reform of CET and the requirement of the "New English Study", the CET-4 after 2005 has included such questions as E-C translation. However, due to the lacking of attention to this ability in daily English teaching, this question has become the most difficult one for students to pass this exam. From the above analysis we can see that this current situation should be changed immediately, and therefore students can have the opportunity of learning English indeed. What we should do is to pay more attention to the teaching and practice of English translation technique from the perspective of the curriculum provision and the teaching arrangement in order to improve students' translation ability.

There are huge differences between English and Chinese in sentence patterns, word orders and ways of expression, which should be paid more attention to in the process of translation. Translation is a relatively comprehensive English ability, in which students need to accumulate some necessary vocabularies and understand some English grammar. In addition, we should also master the English reading techniques skillfully. Therefore, it is necessary for us to practice students' comprehensive ability in order to improve their translation ability.

The Difference between English and Chinese Sentence Structure. Compared with Chinese, English is more simple and direct in expression and it avoids the repetition. However, Chinese is quite the opposite. It usually repeats the same characters or sentences in a passage, which should be paid enough attention in the C-E translation process. In addition, in English, people are used to use some attributive clauses and participial phrases, which seldom appear in Chinese. Another difference exists in the structure of English and Chinese: Chinese has the bamboo-structure and has the clear distinction between framework and joint, and each can be served as an independent unit. Therefore, there exist some figures of speech like parallelism. However, English has the tree-structure, that is to say, every sentence has a clear subject and other elements all rely on the backbone structure, which is also one of the differences between English and Chinese. So the key point in English translation teaching is to teach students to change the English sentences into the integrated bamboo-structure Chinese sentences through some necessary and flexible techniques. In order to improve students' translation ability, what we should do is to let students be familiar with and memorize these features. As a result, students can avoid the appearance of rote in the process of translation, which is also the key point we should pay attention to in the current English translation teaching process.

The Specific Techniques in the Syntactic Translation. In this part, the author of this paper concludes some common translation techniques from the perspective of the syntax according to the practical teaching experience and puts forward his own opinion about the usage of these techniques.

The rearranging-the-order method. That is to say, this method is to keep the translation neat and orderly through rearranging the order of some specific order of sentences in the source text. Specifically, the Subject should always be rearranged in the sentences containing the passive voice, which is to say, to place the Subject to the latter part of the sentence. This method is often used in such sentence structures like "It is/was/has been...that", which includes the grammatical point 
called "it serving as the formal subject". For example, this sentence "About 1845, a canal was constructed across the meadows of the Marsh Farm." is a typical sentence containing the postpositive subject. When we translate this sentence, we should rearrange the order of the Subject and then we can correctly understand its meaning.

The dividing-the-sentence method. It is a translation method which mainly deals with the translation of long sentences in English. The major procedure is to translate a long sentence into several short sentences and to add some essential phrases in order to ensure the readability of the translation. For example, when we translate the sentence "I am Li Hua, who comes from Beijing university, which is the most important universities in China, who is my motherland.", we should divide it into short sentences like "I am Li Hua. I come from Beijing University. Beijing University is the most important universities in China. My motherland is China." In this way, the structure of the whole sentence will become clear.

The turning-the-sentence method. It refers to the process of translating a short sentence in English, or a part of sentence structure into an idiom or a phrase in Chinese, which needs the translator to have relatively high literature ability. For example, the sentence "A movie of me leaving that foxhole would look like a shell leaving a rifle." is a typical sentence which contains a "turning of the subject". Another example is like this: the sentence "The good tidings filled the whole nation with joy." can hardly be translated vividly only on the basis of its literal meaning. However, if we use the turning-the-sentence method to translate this sentence, we can try in this way: “捷报传来，举国上下一片欢腾.” It can be concluded that this translation method will keep the integrity of the translation as well as the true meaning contained in the source sentences.

In addition, generally speaking, there are also other translation methods such as the combining-the-sentence method and the shortening-the-sentence method on the basis of the syntactic structures. When we meet with a specific sentence, we should first make a correct division of the overall structure of the English sentence no matter which translation method we will choose. Therefore, we should not only teach students some typical translation techniques in class, but also provide them with many practical opportunities in order to improve their translation ability.

\section{The Technique of Translating the Attributive Clause}

The attributive clause mainly includes two different types: the restrictive attributive clause and the non-restrictive attributive clause. Specifically, we can choose three kinds of translation method according to the feature of sentence structure. Firstly, when it comes to the restrictive attributive clause, which is relatively close to the antecedent in structure, we often use the rearranging-the-order method to translate it. If the sentence is relatively short, and the clause cannot bring the difficulty for us to understand the meaning of the main sentence, we often use the fore-lying method to translate it. If the sentence is relatively long, we should use the postpositive method to translate it in order to avoid the ambiguity of the sentence.

However, when it comes to the translation of the non-restrictive attributive clause, which is relatively far to the antecedent in structure, the deviation of understanding will appear if we put it in the same structure with the main sentence. Therefore, when we translate the descriptive non-restrictive attributive clause, we should split the attributive clause from the main sentence to make it an independent sentence, which is also the dividing-the-sentence method we have discussed in the above analysis. For example, if we follow the literal meaning of the sentence "The woman is my mother who is in Beijing.” it should be translated into “这是我在北京的母亲.” And it is ambiguous according to the principles of Chinese. Therefore, this sentence should be translated into this: “这是我的母亲，她现在在北京.” From this example we can see that it will accord with the Chinese speaking habits when we translate the sentence by dividing it into small groups. 


\section{The Basic Requirements of Improving the E-C Translation Ability}

Accumulating the Language Materials. Students will be able to realize the important meaning of enlarging their vocabulary and accumulating English knowledge when they learn the E-C translation. And they will take advantage of various kinds of opportunity to enhance their translation ability in their daily studying process. However, the language accumulation here refers not only to the accumulation in English language itself. The E-C translation is the process of the relative transformation between Chinese and English. When students accumulate the basic English knowledge, they should also improve their ability of using their mother tongue Chinese. Only in this way can they get the beautiful translation and avoid the embarrassment of not being able to express some English phrases in Chinese. Therefore, we should encourage students to improve their ability of using Chinese through reading some literature masterpieces.

Enlarging the Breadth of Knowledge. In fact, the materials are always related to the hottest social issues no matter in CET-4 or in recent years' postgraduate entrance examinations. And students can grasp the connotation of the exam questions correctly only from the perspective of the examination itself. Moreover, language itself is the carrier of information, and enlarging students' breadth of knowledge is the helpful force for them to continue their study. Therefore, in college English translation class, teachers should encourage the students to take part in the social activities and broaden their horizon. Only in this way can their comprehensive English ability be truly improved.

\section{Conclusion}

The college English translation teaching is a key point in English teaching process. Because of the inherent difference between the English and Chinese syntax, many students find it hard to grasp this translation ability. However, just as the old saying goes, "The more things change, the more they stay the same." It will be helpful for improving the current translation teaching to teach students how to translate from the perspective of syntactic structure. This paper makes a conclusion about this topic based on the author's own experience, and hopes to be helpful for improving the current college English translation teaching situation.

\section{References}

[1] Xu Xiuhong. The Permeation of the Theory and Technique in the College English Translation Teaching. [J].Journal of Changchun University of Science and Technology (Social Sciences), 2011,02:155-157.

[2] Wang Feng. The College English Translation Teaching from the Perspective of the Comparison between English and Chinese_- the Analysis of the Translation Questions in CET-4 in June, 2011. [J]. Journal of Chongqing University of Posts and Telecommunications (Social Sciences), 2011,06:117-121.

[3] Yu Huina. The Application of the Interactive Teaching Approach based on the Internet to the College English Translation Teaching. [D]. Shandong Normal University. 2015.

[4] Wang Yan. The Application of the Translation Workshop in the College English Major Translation Teaching. [D].Inner Mongolia Normal University. 2013.

[5] Bao Yuhui \& Chen Feng. The Attempt of Introducing the BBC Wild China into the College English Translation Teaching. [J]. The Education of Traditional Chinese Medicine, 2015,06:36-39. 